\title{
Distribution and population genetic variation of cryptic species of the Alpine mayfly Baetis alpinus (Ephemeroptera: Baetidae) in the Central Alps
}

\author{
Marie Leys ${ }^{1,2^{*}}$, Irene Keller ${ }^{3}$, Katja Räsänen ${ }^{1,2}$, Jean-Luc Gattolliat ${ }^{4,5}$ and Christopher T. Robinson ${ }^{1,2}$
}

\begin{abstract}
Background: Many species contain evolutionarily distinct groups that are genetically highly differentiated but morphologically difficult to distinguish (i.e., cryptic species). The presence of cryptic species poses significant challenges for the accurate assessment of biodiversity and, if unrecognized, may lead to erroneous inferences in many fields of biological research and conservation.

Results: We tested for cryptic genetic variation within the broadly distributed alpine mayfly Baetis alpinus across several major European drainages in the central Alps. Bayesian clustering and multivariate analyses of nuclear microsatellite loci, combined with phylogenetic analyses of mitochondrial DNA, were used to assess population genetic structure and diversity. We identified two genetically highly differentiated lineages $(A$ and $B$ ) that had no obvious differences in regional distribution patterns, and occurred in local sympatry. Furthermore, the two lineages differed in relative abundance, overall levels of genetic diversity as well as patterns of population structure: lineage A was abundant, widely distributed and had a higher level of genetic variation, whereas lineage $B$ was less abundant, more prevalent in spring-fed tributaries than glacier-fed streams and restricted to high elevations. Subsequent morphological analyses revealed that traits previously acknowledged as intraspecific variation of B. alpinus in fact segregated these two lineages.

Conclusions: Taken together, our findings indicate that even common and apparently ecologically well-studied species may consist of reproductively isolated units, with distinct evolutionary histories and likely different ecology and evolutionary potential. These findings emphasize the need to investigate hidden diversity even in well-known species to allow for appropriate assessment of biological diversity and conservation measures.
\end{abstract}

Keywords: Alpine biodiversity, Cryptic species, Nuclear microsatellites, Mitochondrial DNA, Sympatry

\section{Background}

Historically, fixed morphological differences have been used to categorize the diversity of life and morphological traits remain important in taxonomy. However, phenotypic differentiation does not always correlate with genetic diversification. On the one hand, phenotypic plasticity can lead to pronounced phenotypic differentiation despite

\footnotetext{
*Correspondence: marie.leys@eawag.ch

'Department of Aquatic Ecology, EAWAG, Swiss Federal Institute of Aquatic Science and Technology, Ueberlandstrasse 133, CH-8600 Dübendorf, Switzerland

${ }^{2}$ Institute of Integrative Biology, ETH-Zürich, CH-8092 Zürich, Switzerland

Full list of author information is available at the end of the article
}

genetic similarity [1]. On the other hand, speciation without morphological divergence may occur, for instance, when mate choice is based on non-visual (e.g., chemosensory, acoustic) cues or when selection promotes morphological stasis [2].

Following the introduction of molecular techniques, it has become clear that a substantial proportion of biological diversity is morphologically hidden: many morphologically delimited species (so called morphospecies) consist of distinct evolutionary lineages that show varying levels of adaptive divergence and reproductive isolation [2]. In the most extreme case, multiple cryptic 
species may coexist in sympatry without interbreeding. Such cryptic species complexes are more widely distributed than previously thought, being reported for diverse taxonomic groups and across various ecosystems [3, 4].

Identifying and characterizing cryptic species, and the failure to do so, have far-reaching implications for basic and applied research. Critically, due to their distinct evolutionary histories, cryptic species may possess unique adaptations and evolutionary potential, and hence must be considered as separate evolutionarily significant units [5]. Ignoring the potential biological differences between cryptic species may render many biomonitoring, ecological risk assessment and conservation measures inappropriate [6-9].

The recognition of cryptic species, as well as their evolutionary histories and ecological requirements, is also crucial for predicting how climate change affects biodiversity $[7,10]$. Climate change impacts are particularly alarming in alpine landscapes due to drastic environmental changes following increased temperatures and glacial retreat [11]. In glacial headwaters, severe alterations in hydrology and temperature regimes are threatening ecologically specialized and often endemic freshwater organisms [12, 13] even without acknowledging cryptic diversity [10].

Importantly in this context, cryptic species are commonly reported in freshwater invertebrates [9, 14-17], and the mayfly genus Baetis (Ephemeroptera) comprises particularly remarkable examples of hidden diversity. Thus far, population genetic and phylogenetic studies have reported cryptic species complexes within $B$. bicaudatus [18], B. rhodani [19], B. vernus [20] and B. harrisoni [21]. The presence of multiple cryptic lineages has also been suggested within B. alpinus [22-25], a widespread, abundant and eurythermal alpine mayfly. The importance of understanding mayfly diversity is further emphasized by their wide use as biological indicators in ecotoxicological studies, and assessments of habitat quality and restoration success (e.g., $[26,27])$.

In this study, we investigated patterns of genetic diversity in B. alpinus across the Swiss Alps using both nuclear microsatellite and mitochondrial DNA (mtDNA) markers. First, we used the combination of these two types of markers to reliably identify putative cryptic lineages testing the hypothesis of lineage separation. We followed the unified species concept [28], considering as separate species groups that are clearly distinguishable based on their multi-locus genotypes, with no or few intermediates when they occur in sympatry [29]. DNA barcoding, which relies on a single marker (typically the mitochondrial Cytochrome Oxidase I), has been extensively used for species delineations in animals [30], including mayflies [31]. However, shortcomings of singlegene approaches, such as the presence of pseudogenes [32], introgression [33] or incomplete lineage sorting [34] stress the need of a broader strategy. In addition, many studies report a lack of congruence of evolutionary histories inferred from mtDNA and nuclear genomes (i.e., mitonuclear discordance [35]), emphasizing the importance of multi-locus approaches for a reliable assessment of genetic relationships among populations and species. Secondly, we used the nuclear microsatellite markers for a more detailed assessment of the extent of reproductive isolation among the putative cryptic lineages (e.g., [36-39]) and the population genetic structure within lineages. The latter is of interest as it reflects behavioral, historical and demographic differences between cryptic lineages as well as patterns of gene flow within lineages [40, 41].

We sampled $B$. alpinus species group from multiple basins in the central Alps in Switzerland. We used both large scale (regional) and within basin (local) sampling, combined with population genetic analyses, to test the following predictions. First, we tested for the presence of cryptic species within $B$. alpinus. These would be evident as strongly distinct lineages in both mtDNA and nuclear microsatellite markers. Our molecular data confirm the presence of two genetically highly distinct groups within $B$. alpinus (henceforth called lineage $A$ and $B$ ) as well as some individuals from the closely related and superficially morphologically similar B. melanonyx. To gain insight into putative differences among these $B$. alpinus lineages, we investigated their relative abundances, habitat affinities and differences in population genetic structure, and tentatively re-analyzed morphological variation of lineages $A$ and $B$. In particular, we tested whether the different lineages i) are associated with different environments (here, glacier-fed vs. springfed streams) - indicating ecological differences arising from either differences in habitat preference or local adaptation, ii) differ in population genetic variation and population structure - reflecting potential differences in evolutionary history as well as population demography, and iii) exhibit morphological differences in traits used in taxonomic identification of species.

\section{Methods}

\section{Study species}

Mayflies (Ephemeroptera) have aquatic egg to larval stages, strictly associated to freshwater habitats, followed by two short-lived winged stages: the pre-reproductive subimago and the sexually mature imago. Mayflies spend the longest part of their life cycle as larvae, the development of which is strongly dependent on water temperature [42, 43]. The length of the (pre-)adult stages is often shorter than one day. In the imaginal stage, males form swarms in which females fly into to mate. Mayfly females die after egg laying and males soon after mating. Dispersal occurs during adult aerial flight along streams as well as passive (drift) dispersal of larvae [44]. 
Due to their particular life cycle and habitat requirements, mayflies possess a low dispersal potential [16].

The genus Baetis was divided into 11 species groups [45], with some of them recognized as subgenera or genera (e.g. [17]). Among these, Baetis group alpinus encompasses 11 species [46], all but B. alpinus s.s. and $B$. melanonyx having restricted spatial distributions or being considered as endemic (e.g. [47, 48]). In particular, three species of the $B$. alpinus group are reported from Switzerland, namely: B. alpinus (Pictet) s.s., B. melanonyx and B. nubecularis. B. alpinus s.s. is a widespread and abundant alpine mayfly of the Palearctic region, reported from the Iberian Peninsula to the Ukrainian Carpathians [43, 49]. B. melanonyx is also widely distributed in the West Palearctic from the Iberian Peninsula to Ukraine. B. nubecularis is restricted to a few localities in the Swiss and French Jura mountains [48].

B. alpinus larvae are eurythermal and found in swiftflowing stony streams between 200 and at least $2600 \mathrm{~m}$ above sea level (a.s.l.). After mating, similarly to other Baetis species, adult females usually fly upstream from the emergence site and oviposit underneath large, stable protruding rocks [50], where eggs develop for several weeks until they hatch [42]. The life cycle of B. alpinus is described as plastic with regard to emergence timing and voltinism (which can be tri-, bi-, uni- or semivoltine) $[43,51-54]$ and is thought to be environmentally influenced [55]. B. melanonyx occurs in rhithral streams mainly between 600 and $1400 \mathrm{~m}$ a.s.l. In syntopic populations of $B$. alpinus, larval abundance was observed to decrease with elevation $[46,56]$. $B$. melanonyx is distinguished from $B$. alpinus by a set of morphological traits [57].

\section{Study area and sample collection}

This study investigated the genetic structure of B. alpinus at both regional and local scales. To examine regional patterns, 24 sites were sampled from multiple basins within each of four major European drainages in Switzerland (Rhine, Rhone, Danube and Po; Fig. 1a). The elevation of the sampling sites ranged from 476 to $2470 \mathrm{~m}$ a.s.l. To examine local-scale patterns, an additional 24 sites were sampled within three glacier-fed headwater basins in the Rhine (Ri), Rhone $(R o)$ and Danube $(D a)$ drainages (Fig. 1b). In the local scale sampling, four or five springfed tributaries $(\mathrm{T})$ and two to five glacial main-stream $(\mathrm{M})$ sites were sampled along a longitudinal gradient downstream from the glacial snout (distance of sites from the glacier snout was min. $90 \mathrm{~m}$ and max. $6310 \mathrm{~m}$, Fig. 1b). We chose this environmental contrast as B. alpinus is known to occur in both types of habitats and because main glacial streams and tributaries strongly differ in key ecological factors likely affecting performance of baetids. In particular, glacial streams exhibit colder but more fluctuating daily temperatures, higher stream-bed instability and more turbid waters relative to the more stable physico-chemical conditions of spring-fed streams [58, 59].

At each sampling site, mid to last-instar Baetis larvae were collected using a kick-net. Five kick-net samples were taken 3-5 m apart in an upstream direction with 40-50 larvae subsequently preserved in $96 \%$ ethanol. For logistic reasons it was not feasible to taxonomically identify all individuals, but a few individuals per site were identified to the species level using taxonomic keys [57, 60]. Sampling was carried out from November 2011 to October 2012 and was completed the same day for all sites within a basin. Additional file 1: Table S1 provides additional information on the sampling locations.

\section{Molecular procedures}

For genetic analyses, total genomic DNA was extracted from either complete larva or head capsules using a standard salting-out procedure [61].

\section{Microsatellite genotyping}

A total of 1591 individuals (average \pm SD per site $=$ $33.2 \pm 9.0$ ) were genotyped at 10 unlinked and polymorphic microsatellites, including both cDNA- (Ba_c1, Ba_c2, Ba_c3, Ba_c4) and genomic DNA-derived (gDNA, Ba_g1, Ba_g2, Ba_g3, Ba_g4, Ba_g5, Ba_g6) markers. The markers were developed by Ecogenics (Zürich, Switzerland) and are described in detail in the online supplement (Additional file 1: Table S2). cDNA-derived microsatellites were included because they tend to be more conserved, resulting in improved transferability across related species [62]. Interspecific transferability was considered important in this system where the presence of highly diverged lineages was expected based on previous work on B. alpinus and closely related taxa (e.g., $[19,23])$. These markers also amplified DNA of B. alpinus' sister species, B. melanonyx.

Amplification by polymerase chain reaction (PCR) was performed in two separate multiplex reactions (Additional file 1: Table S2). PCR mixtures included $1 \mu \mathrm{L}$ of DNA (at unknown concentration), $5 \mu \mathrm{L}$ of QIAGEN Multiplex PCR Master Mix, and $\mathrm{ddH}_{2} \mathrm{O}$ to make up a total reaction volume of $10 \mu \mathrm{L}$. Primers were used at different concentrations to achieve similar signal intensities at the different loci (Additional file 1: Table S2). PCR cycling conditions were as follows: $15 \mathrm{~min}$ of denaturation at $95^{\circ} \mathrm{C}$, followed by 30 cycles at $94{ }^{\circ} \mathrm{C}(30 \mathrm{~s}), 56{ }^{\circ} \mathrm{C}(90 \mathrm{~s})$, and $72{ }^{\circ} \mathrm{C}(90 \mathrm{~s})$, followed by a final elongation step of $10 \mathrm{~min}$ at $72{ }^{\circ} \mathrm{C}$. After dilution of the PCR products, fragments were separated using an ABI 3730xl DNA Analyzer (Applied Biosystems) and alleles were identified according to the PCR product size relative to a size standard (GeneScan ${ }^{\text {tix }}$ LIZ500; Applied Biosystems). The electropherograms 


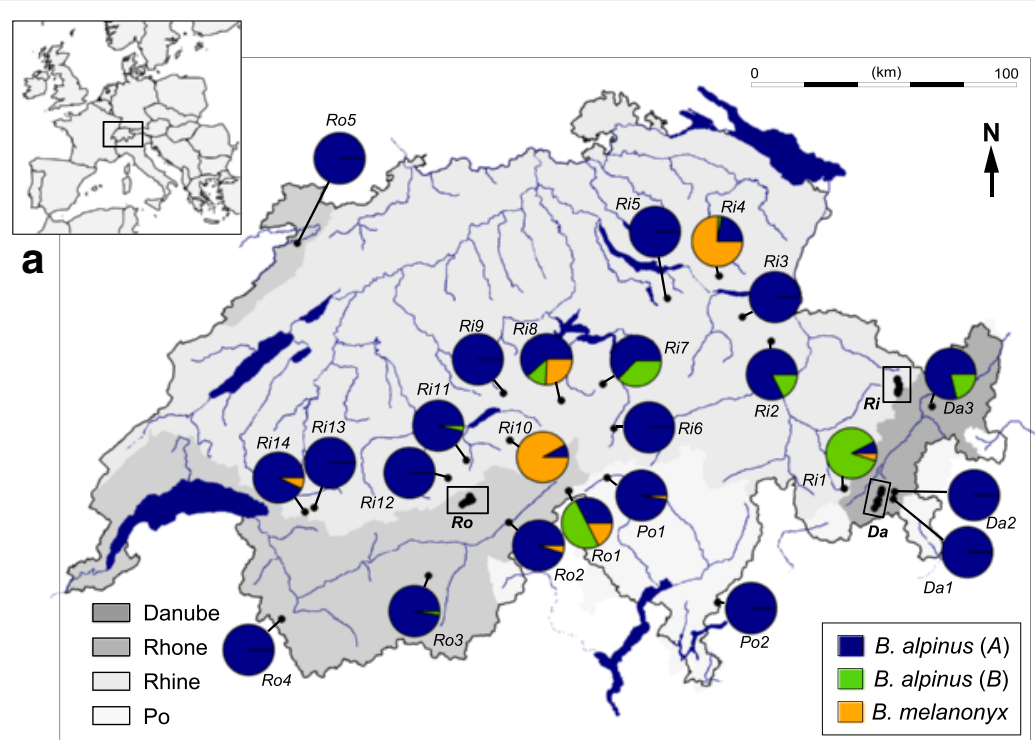

b Ri Jörisee proglacial lakes
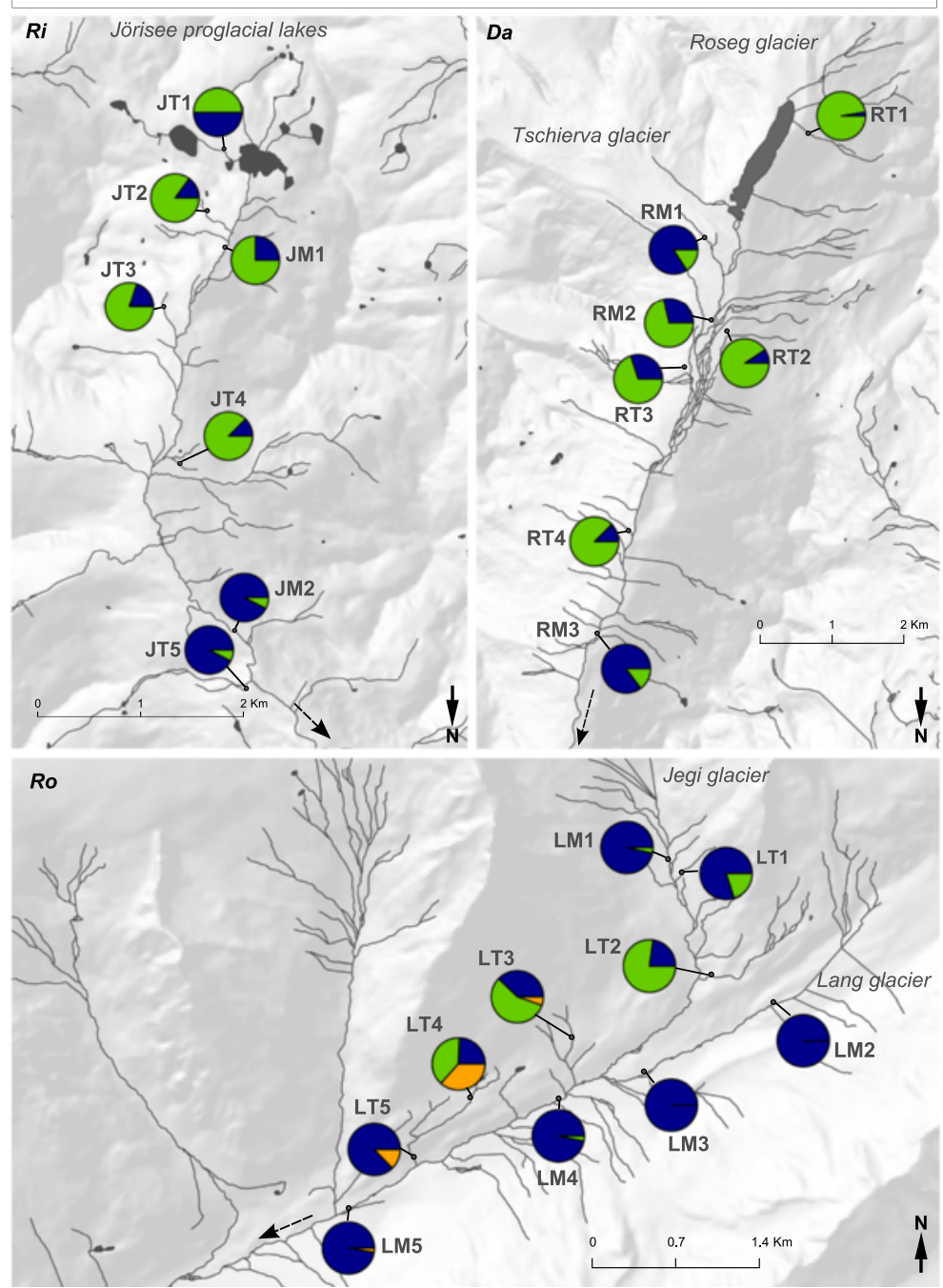

Fig. 1 (See legend on next page.) 
(See figure on previous page.)

Fig. 1 Sampling sites and the distribution of two B. alpinus cryptic lineages ( $A$ and $B$ ) and B. melanonyx within four major European drainages (Danube: Da, Rhone: Ro, Rhine: Ri and Po: Po) in the Swiss Alps. Sites are depicted at $\mathbf{a}$ the regional-scale and $\mathbf{b}$ within basin scale (labelled Ri, Ro and $D a$ and by boxes in (a). In $\mathbf{b}$, the first letter of the location name indicates the basin ( $J=$ Joerisee, $R=$ Roseg, $L=$ Loetschental) and the second letter the river type ( $M=$ main channel, $T=$ tributary). Dotted arrows show river flow direction

were analyzed and manually edited using GENEMAPPER 3.7 software. To minimize the rate of genotyping errors, a second round of PCR and electrophoresis was performed for individuals with dubious multilocus genotypes (i.e., those with missing data or displaying rare alleles).

\section{mtDNA COI sequencing}

In a subset of 44 individuals, we sequenced a part of the Cytochrome Oxidase subunit I (COI) to determine the degree of mtDNA divergence among the cryptic species identified based on microsatellite markers (see Results), and to facilitate the comparison of our results with those of Finn et al. [22, 23]. The specimens were selected according to their geographic origin and cryptic species assignment (see Results). The primers LCO1490 and HCO2198 [63] were used to amplify a 658 bp fragment. Reactions contained $5 \mu \mathrm{l}$ of DNA (unknown concentration), $12.5 \mu \mathrm{l}$ KAPA2G HiFi HotStart Ready Mix (Kapa biosystems), $1.25 \mu \mathrm{l}$ of each primer $(10 \mu \mathrm{M})$ adjusted to a final volume of $25 \mu \mathrm{l}$ with $\mathrm{dd}_{2} \mathrm{O}$. Initial denaturation ( 3 min at $95^{\circ} \mathrm{C}$ ) was followed by 40 cycles of $15 \mathrm{~s}$ at $94{ }^{\circ} \mathrm{C}$, $15 \mathrm{~s}$ at $48{ }^{\circ} \mathrm{C}, 15 \mathrm{~s}$ at $72{ }^{\circ} \mathrm{C}$, and a final extension of $72{ }^{\circ} \mathrm{C}$ for 1 min following Kapa standard instructions. PCR products were purified using the Wizard SV96 standard protocol (Promega) prior to sequencing (Microsynth, Balgach, Switzerland). When low concentration amplicons were obtained, the amplification was repeated twice, and both reactions were pooled in the purification step. Sequences were edited using CODONCODEALIGNER 5.1.5 (CodonCode Corporation, Centerville, MA, USA) and aligned using ClustalW in BIOEDIT 7.2.5 [64].

\section{Statistical analysis \\ Characterisation of microsatellite markers}

All microsatellite loci were tested for variability and departures from Hardy-Weinberg equilibrium (HWE) within samples expected to be panmictic (i.e., from both the same location and genetic group defined here-after as "population"; see clustering analysis below). All HWE tests were performed with a minimum sample size of eight individuals using the randomisation procedure implemented in FSTAT 2.9.3.2 [65]. Linkage Disequilibrium (LD) between pairs of loci was assessed in GENEPOP 4.0.1.1 [66]. Using the same software, the frequency of null alleles was estimated according to Dempster et al. [67]. All loci were found to be highly polymorphic in all B. alpinus populations, and we found no consistent deviations from HWE or deviations from linkage equilibrium. In contrast, B. melanonyx showed high probabilities of null alleles for some site-locus combinations together with significant deviation from $\mathrm{HW}$ genotypic proportions. We therefore refrained from any further detailed population genetic analysis of this species. Detailed information on the number of alleles, observed and expected heterozygosities, and estimated null allele frequencies is provided in Additional file 1: Tables S4 and S5.

\section{Cryptic lineage delimitation}

For the microsatellite markers, cryptic species were identified in accordance with the 'genotypic cluster' definition, within the unified species concept framework [28]. Under this definition, distinct genotypic groups are considered as separate species when they show no or very limited interbreeding upon contact and, as a consequence, follow largely independent evolutionary trajectories [29].

The Bayesian clustering approach of STRUCTURE 2.3.4 [68] was used to identify genetic substructure within the full dataset and assign individual genotypes to specific genetic groups. We used an admixture model and correlated allele frequencies [69] without any prior information on the putative population affiliation of individuals and with $2 \times 10^{6}$ Markov chain Monte Carlo (MCMC) iterations following a burn-in period of $1 \times 10^{5}$ iterations. The likelihood of different numbers of genetic clusters $(K)$ was assessed for $K=1-30$ using 30 runs per $K$. The ad hoc statistic $\Delta K[70]$ was calculated and further visual exploration of the results was performed (see [71]) to determine the most likely value of $K$. Similarity coefficients between runs and the average matrices of individual membership proportions were estimated using CLUMPP 1.1.2 [72]. As multimodality was observed for all $K$ (Additional file 2), the group of solutions most frequently observed among the 30 replicates was averaged and used for interpretation. Clusters were visualized using DISTRUCT 1.1 [73].

On the same data, we also performed a Discriminant Analysis of Principal Components (DAPC), a model-free multivariate method to identify genetic clusters, genetic clines and hierarchical structures [74]. The discriminant analysis was based on 60 principal components accounting for $87 \%$ of the total genetic variation. The Bayesian Information Criterion (BIC) was used to determine the optimal number of clusters [74]. All analyses were conducted using adegenet for R.3.13 [75]. 
Congruence of mtDNA clades and nuclear genetic clusters For the mtDNA markers, we created an alignment of the $44 \mathrm{COI}$ sequences (including $41 \mathrm{~B}$. alpinus and $3 \mathrm{~B}$. melanonyx) produced in our study and $42 \mathrm{~B}$. alpinus sequences from GenBank to gain insights into genetic variation across multiple mountain massifs within the range of $B$. alpinus (see Additional file 1: Table S3, $[22,23,25])$. We also included two B. nubecularis and one B. melanonyx unpublished sequences (provided by S. Rutschmann and M.T. Monaghan obtained as part of the FREDIE project) to gain insight into the extent of genetic divergence between $B$. alpinus cryptic lineages compared to taxonomically described species of the $B$. alpinus group. Using a fragment of 613 bp from all 89 sequences, 70 unique haplotypes were identified using the haplotype function in the ape package for $\mathrm{R}$ [76]. A maximum likelihood (ML) gene tree was inferred on all unique COI haplotypes using the software PhyML 3.01 [77] and the TN93 + G + I substitution model that best fit the data according to the Akaike information criterion (AIC). The evolutionary model selection was conducted using both the phymltest function of the $\mathrm{R}$ package ape and PhyML 3.01 software [76, 77]. Branch support was calculated with 500 bootstrap replicates. Baetis rhodani was used as an outgroup (published sequence, Additional file 1: Table S3). Pairwise distances assuming the TamuraNei nucleotide substitution model were computed using the dist.dna function of the ape package [76].

To derive mtDNA clades, we performed a Parsimony haplotype network analysis (Additional file 3). Next, a simple graph analysis using all unique COI haplotypes and the function genegraph implemented in the $\mathrm{R}$ package adegenet was completed [75].

\section{Comparing the cryptic lineages in relative abundance and spatio-ecological attributes}

We found two genetically strongly distinct $B$. alpinus lineages (henceforth called lineage $A$ and $B$ ). A small subset of specimens $(N=112)$ identified as $B$. melano$n y x$ were recovered as a monophyletic lineage. The relationship between the relative abundance of $B$. alpinus lineage $A$ and $B$ and spatio-ecological attributes (i.e., elevation, drainage and stream-type) was tested using generalized linear models with logit link and binomial error. These analyses were conducted separately at the regional and local scales. First, at the regional scale, we tested for the effect of elevation and drainage (fixed effects) on the relative abundance of the two lineages. To reduce bias due to differences in sampling design among basins that included regional $v s$. local scale data, one site was randomly selected within the $R o, R i$ and $D a$ basins for regional analyses (hence, data consisted of 27 sites). Secondly, at the local scale (i.e., 24 sites), we tested for the effects of stream-type (glacial main stream sites $v s$. spring-fed tributaries) and basin ( $R o, R i$ and $D a$ ) by including these as fixed factors in the model. As overdispersion was detected for both the regional and local models, we fit quasi-binomial models and used $F$-tests for model comparison [78]. Terms were dropped from the model in a stepwise manner if their removal did not lead to a significant increase in deviance. The generalized linear models were run using the library stats for R 3.1.3 [79].

\section{Population genetic structure within B. alpinus cryptic lineages}

To test for genetic substructure within lineage $A$ and $B$, we used nuclear microsatellite markers and three complementary approaches: 1) Bayesian clustering (STRUCTURE), 2) multivariate ordination without considering the geographic origin of the samples (DAPC), and 3) multivariate ordination with spatial information (spatial Principal Component Analysis; sPCA [80]). Each individual was assigned to a cryptic lineage based on the maximum cluster membership probability estimated by DAPC as this method does not make any assumption with respect to mating system, population structure or allelic frequency models.

STRUCTURE and DAPC were run as described above, but we assessed only $K=1-10$ in the STRUCTURE analysis. The sPCA complements the first two methods by explicitly identifying spatial patterns of genetic structuring (e.g., clines) across the landscape and accounting for spatial autocorrelation caused, for instance, by spatially limited mating or uneven distribution of sampling sites $[81,82]$. We used the Gabriel graph to define which populations are neighbours in the sPCA algorithm. Following the methods in Jombart et al. [80], we tested for global (neighbouring populations are more similar than expected) and local (neighbouring populations are more dissimilar than expected) spatial structures using permutation tests with the number of axes retained based on the sPCA eigenvalue decomposition. If significant genetic structure was detected, we qualitatively identified spatial allele frequency patterns by visualizing the entity scores on a geographic map. The scores of the first two principal components were simultaneously represented using the RGB (red, green and blue) color model as in Menozzi et al. [83]. All analyses were performed using the adegenet package [80] for $\mathrm{R}$ 3.1.3 [79].

Population differentiation across all populations was assessed using classical $F$-statistics according to Weir and Cockerham [84]. A permutation test was used to determine whether $F_{\mathrm{ST}}$ values were significantly different from 0 for each locus and over all loci (10,000 randomisations of multilocus genotypes among populations). Further, we tested for an association between geographical and genetic distance between populations accounting for genetic 
substructure using a partial Mantel test based on three distance matrices: 1) Pairwise genetic distance $\left(F_{\mathrm{ST}}\right)$ between populations of at least eight individuals, 2) pairwise Euclidean distance, and 3) a 0/1 matrix indicating if two populations belong to the same or different subgroups within cryptic lineages. To create this last matrix, we assigned the population as a whole to the subgroup where, averaged across all individuals, it had the highest membership probability. The significance of $r$ values was tested with a partial Mantel test (10,000 permutations) performed in the package ecodist for R [79].

Genetic diversity within each B. alpinus lineage was examined based on all populations with at least eight individuals by calculating the total and mean number of alleles $\left(A_{t}\right.$ and $A_{m}$, respectively), allelic richness $\left(A_{\mathrm{r}}\right)$ and gene diversity $\left(H_{\mathrm{E}}\right)$ in FSTAT 2.9.3.2 [65]. Allelic richness was estimated using the rarefaction approach proposed by El Mousadik and Petit [85] based on eight diploid individuals. Private allelic richness $\left(A_{\mathrm{r}} P\right)$ was computed following the rarefaction procedure $(n=8)$ in the ADZE software [86]. Levels of genetic polymorphism $\left(A_{\mathrm{v}} A_{\mathrm{r}} P\right.$, and $\left.H_{\mathrm{E}}\right)$ were compared between $B$. alpinus lineages. Differences were tested using the Kruskal-Wallis Rank Sum test and the multiple comparison test implemented in the $\mathrm{R}$ package pgirmess [87].

\section{Morphological differences between cryptic lineages}

The initial identification of the B. alpinus specimens was based on standard taxonomic criteria related to (in particular) mouth parts, legs and tergites of larvae [57]. Upon genetic identification of strongly distinct lineages, we selected a subset of samples for which genetic lineage was known for a tentative morphological screening to confirm whether the lineages were indeed morphologically indistinguishable. A detailed microscopic examination of morphological characters was conducted on a subset of 23 B. alpinus larvae $\left(\mathrm{N}_{A}: 12 ; \mathrm{N}_{B}: 11\right)$. These specimens were selected according to their lineage and genetic subgroup identity, and collected from the same site (LM3 in the Ro basin) when possible. As some genetic subgroups were only present either in eastern or western Switzerland, additional specimens belonging to genetic subgroups not present in LM3 were selected in Da. Specimens, preserved in ethanol (96\%), were dissected using a stereo-microscope and mounted on slides in Canadian balsam after a short stay in Creosote solution. Morphological characters included: i) the number of spine-like setae at the apex of the maxillary palp, ii) the number of rows of long setae on the dorsal margin of the femora, iii) the presence and number of setae at the apex of the tarsus, iv) the triangular spines of the distal margins of tergum IV, v) the presence of micropores on tergum IV, vi) the presence and number of scales of tergum IV, and vii) the margins of the gills IV.

\section{Results}

Evidence for cryptic lineages

Bayesian clustering of the microsatellite data revealed three distinct genetic groups, of which two corresponded to $B$. alpinus and one to $B$. melanonyx (termed $A, B$ and B. melanonyx; Fig. 2; Additional files 2 and 4). This grouping was strongly supported by concordant DAPC results, with nearly identical individual assignment $(99.7 \%)$ to the genetic groups identified by STRUCTURE (Fig. 2; Additional file 4). The magnitudes of differentiation, as indicated by between-lineage or species pairwise $F_{\mathrm{ST}}$ s, were $F_{\mathrm{ST}}=0.189$ for $A v s B, F_{\mathrm{ST}}=0.234$ for $A v s B$. melanonyx and $F_{\mathrm{ST}}=0.318$ for $B$ vs $B$. melanonyx (all $P<0.001)$. The strong separation of the genetic clusters was due to both private alleles at some loci and allele frequency differences at all loci. A total of 1543 out of 1591 genotypes $(97.0 \%)$ could be clearly assigned to one of the three clusters (membership probability $\geq 0.85$ ) and only 48 genotypes (3.0 \%) showed admixed membership proportions.

In total, 27 different haplotypes (25 B. alpinus and $2 B$. melanonyx) were identified in our set of $44 \mathrm{mtDNA}$

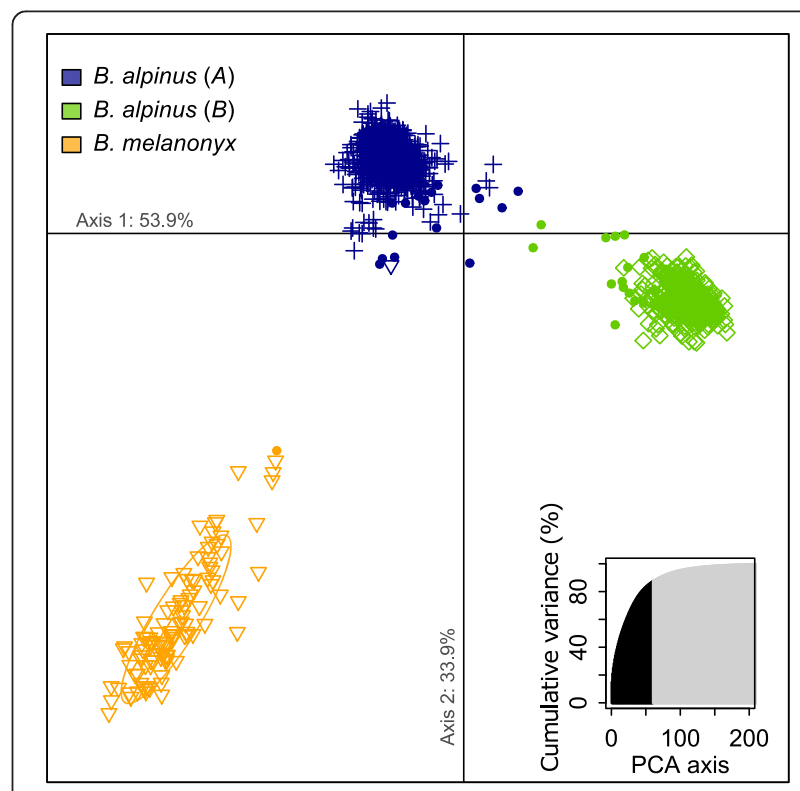

Fig. 2 Clustering analysis of multilocus genotypes of 1591 individuals of $B$. alpinus species group based on 10 microsatellite markers. The DAPC scatterplot shows the first two principal components on the $X$ and $Y$ axes. Each colored dot represents an individual genotype assigned to one of the three clusters by DAPC (colors and ellipses), with symbols corresponding to each genetic group defined by Bayesian clustering analysis of STRUCTURE: $B$. alpinus lineage $A$, crosses; $B$. alpinus lineage $B$, diamonds;

B. melanonyx, triangles. Filled dots indicate admixed individuals with a cluster membership coefficient $<0.85$ in the STRUCTURE analysis.

The number of principal components retained and their cumulative variance explained are highlighted in black in the insert. The proportion of variance captured by the first and second DAPC axes is indicated on each axis 
sequences. Our mtDNA sequences, together with those from GenBank, yielded a total of 70 haplotypes. In our data, the clustering observed based on mtDNA sequences matched that based on microsatellite genotypes (Fig. 3). Overall, haplotype Parsimony networks and genetic transitive clusters yielded similar results (Additional files 3 and 5). Mean sequence divergence, assuming the Tamura-Nei nucleotide substitution model, varied between $0.2-6.9 \%$ within clades (1.2 and $4.5 \%$ within lineages $A$ and $B$, respectively) while genetic divergence among clades ranged from 4.9 to $27.1 \%$ (18.9 \% between $A$ and $B$ lineages; see Additional file 1: Table S4).

\section{Relative abundance and spatial distribution of the $B$. alpinus lineages and $B$. melanonyx}

Both $B$. alpinus lineages occurred in several major European drainages ( $B$ was not found in the Po for which only few samples were available). However, the $B$. alpinus lineages showed pronounced differences in abundance: 1001 individuals were assigned to lineage $A$ and 478 to $B$, indicating that $A$ is much more abundant than lineage $B$. Some 112 individuals belonged to $B$. melanonyx which occurred only at eight sites. Mitochondrial DNA sequences revealed high genetic similarity of Swiss haplotypes of each lineage with those from other mountain ranges (central Apennines, Ligurian Apennines, Pyrenees and Sierra Nevada; see Fig. 3 and Additional file 1: Table S3), suggesting a wider European distribution of the lineages found in the Central Alps.

Spatial co-occurrence of the two B. alpinus cryptic lineages was common (Fig. 1), whereby both lineages were present in 29 of the 48 sites. At the regional scale, the relative abundance of lineages $A$ and $B$ showed a significant association with elevation, with lineage $B$ being more abundant at higher elevations (Elevation: $F=12.87$, $P=0.002$, Drainage: $F=0.52, P=0.673$, see Additional file 1: Table S6; Figs. 1 and 4). At the local scale, lineages $A$ and $B$ differed in relative abundance in relation to stream-type, with lineage $B$ being more abundant in groundwater-fed tributaries and $A$ in glacier-fed main streams (Stream-type: $F=9.42, P=0.006$ ). There was

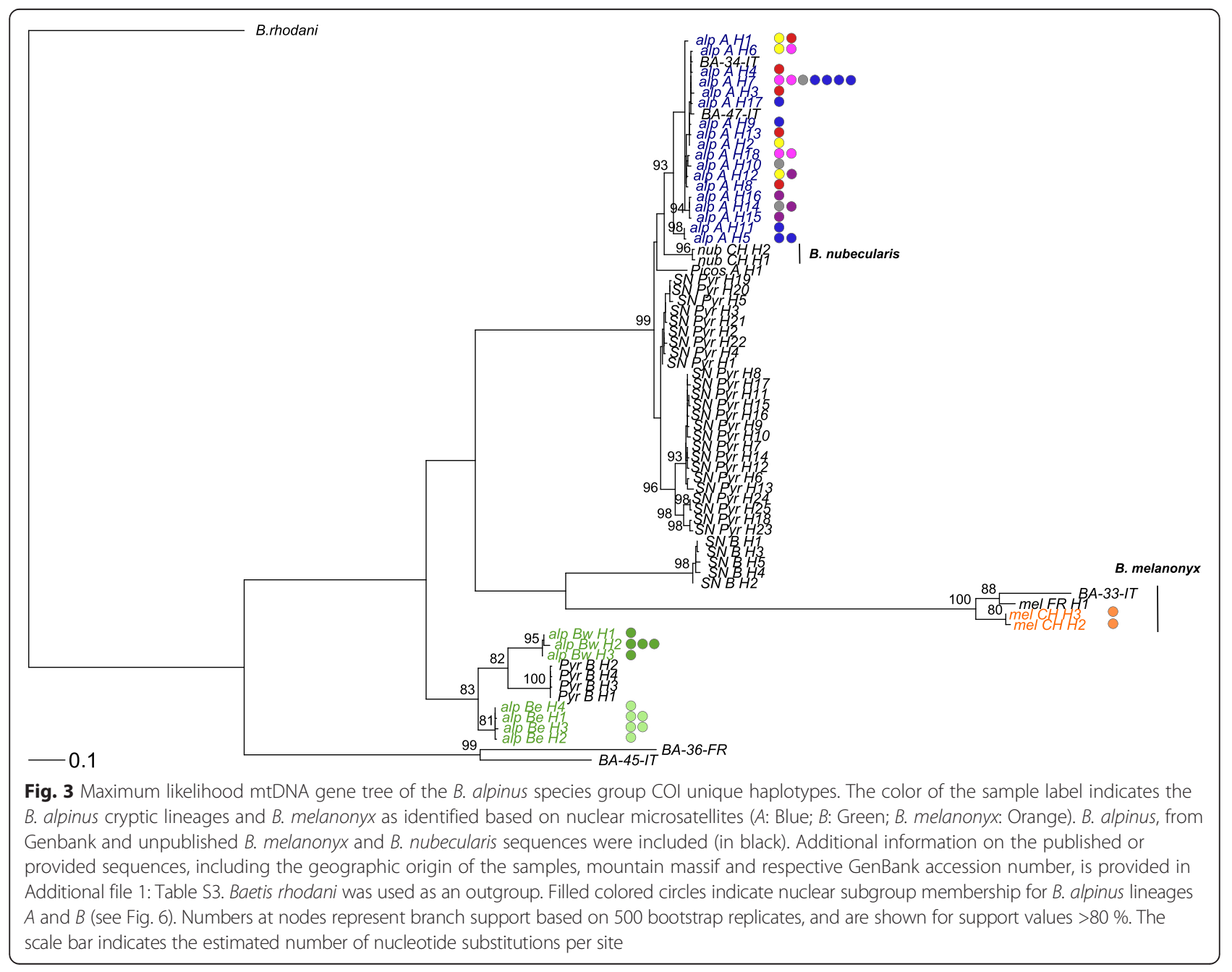




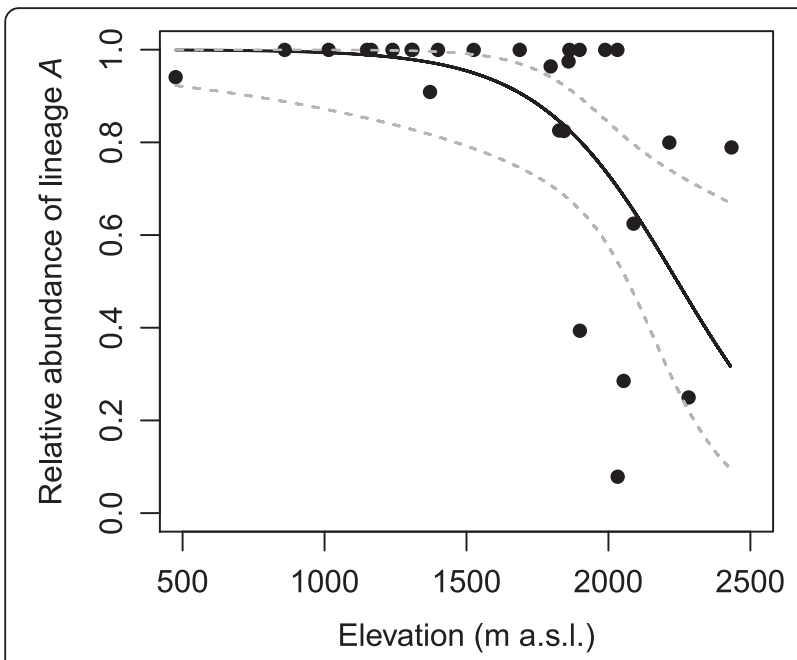

Fig. 4 Relative abundance of $B$. alpinus lineage $A$ versus lineage $B$. Fitted line of the optimal quasi-binomial model including elevation as the only explanatory variable. The grey dotted lines indicate $95 \%$ confidence intervals

also an association of lineages with particular drainages (Drainage: $F=4.66, P=0.022$, Additional file 1: Table S6; see Fig. 1b).

\section{Population genetic variation within the lineages}

In accordance with differences in relative abundance of the lineages, genetic diversity, as measured by $H_{E}$ and $A_{r}$, was higher in $B$. alpinus lineage $A$ than in $B$ (Fig. 5), while private allelic richness $\left(A_{r P}\right)$ did not differ significantly between the two lineages.

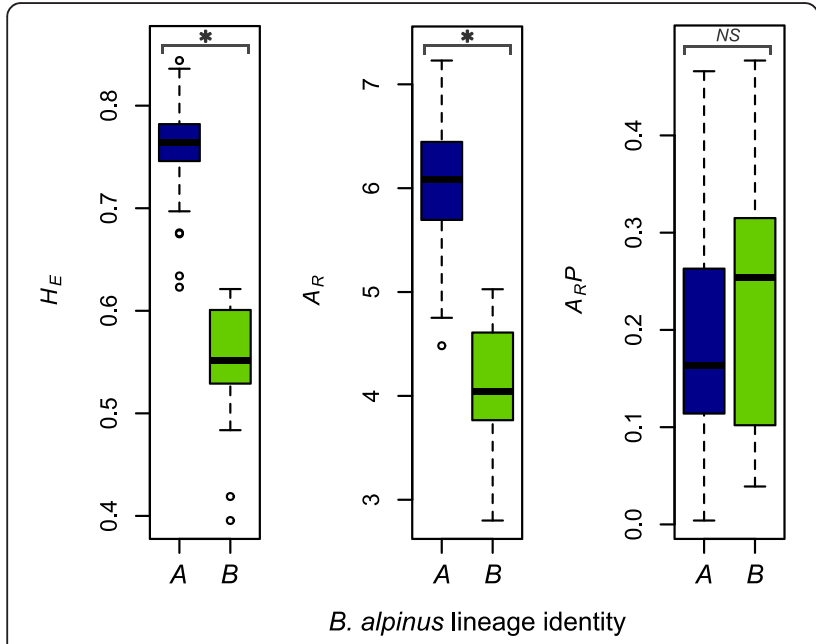

Fig. 5 Genetic diversity estimates (expected heterozygosity $H_{E}$, allelic richness $A_{r}$, and private allelic richness $A_{r} P$ ) for the two $B$. alpinus lineages $A$ and $B$. Box-plots indicate the median (horizontal line), the $25^{\text {th }}$ and $75^{\text {th }}$ percentiles (bottom and top of each box), and the minimum/maximum values (vertical dashed lines). ${ }^{*}=P<0.01$
Further substructuring within the $B$. alpinus lineages was evident. For lineage $A$, Bayesian clustering indicated two peaks of $\Delta K$ at $K=3$ and $K=6$. Visual inspection of the STRUCTURE barplots indicated that plots for $K=6$ were still informative with respect to population substructure (Fig. 6a, Additional file 4). In some populations, most individuals were assigned to a single genetic subgroup (Fig. 6a), whereas many individuals showed contributions from multiple subgroups (i.e., admixture). For lineage $B$, STRUCTURE results indicated the presence of two subgroups (Fig. 6a, Additional file 4).

The within-lineage genetic polymorphisms showed some geographical structure (Figs. $6 \mathrm{~b}$ and 7 ). For lineage $A$, an east-west cline in SPCA scores was observed (significant global structure, $P<0.001$; Fig. 7$)$. The mean population membership probabilities for each of the six genetic subgroups detected within lineage $A$ by STRUCTURE (Fig. 6) indicated that different subgroups were common in different regions of the study area: for instance, the "red" subgroup in eastern Switzerland, and "grey" and "pink" in central/western Switzerland (Fig. 6b). Interestingly, there were also several cases where neighbouring sites had substantially different genetic composition. This was especially the case in the centre of the sampling area, where, for instance, a distinct genetic group of lineage $A$ was observed in spring-fed tributaries in Loetschental (LT populations; purple in Fig. 6b, dark brown in Fig. 7c).

For lineage $B$, STRUCTURE analyses indicated two genetic subgroups, whereby one subgroup was more abundant in central/western and the other in eastern Switzerland (Fig. 6b, Additional file 4). Populations from the same region (i.e., eastern $v s$. western) tended to be similar even when they were in different major drainages (e.g., Rhine and Danube in eastern Switzerland; Rhine and Rhone in western Switzerland; Fig. 6b). Consistent with the Bayesian clustering results, an east to west gradient in sPCA scores was also evident in lineage $B$ (significant global structure, $P<0.001$; Fig. 7). Interestingly, nuclear $B$ subgroups matched the mtDNA COI groupings (Fig. 3).

Within lineage population pairwise $F_{\mathrm{ST}} \mathrm{S}$ ranged from 0.007 to 0.156 and from 0.003 to 0.142 for lineage $A$ and $B$, respectively (Fig. 6c). In both lineages, partial Mantel tests indicated significant correlations between pairwise population genetic distances $\left(F_{\mathrm{ST}}\right)$ and Euclidean geographical distances once the effect of genetic substructure on population differentiation was taken into account (A: $r=0.135, P=0.028 ; B: r=0.492, P<0.001)$.

\section{Morphological differences between $B$. alpinus lineages}

The morphological analysis revealed that some morphological traits previously assumed to reflect within species variation [88] were able to consistently distinguish lineages $A$ and $B$. The number of setae at the apex of the 


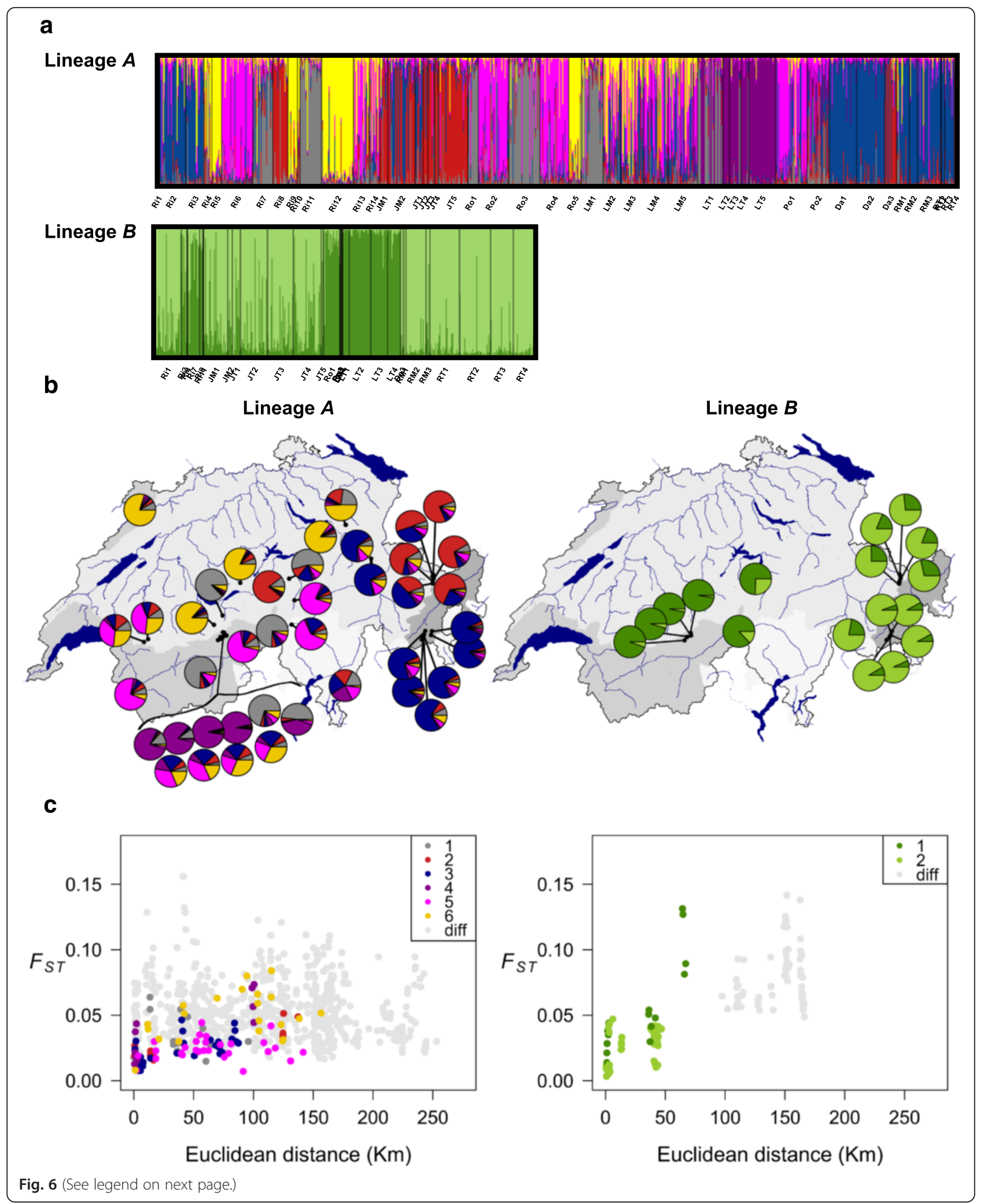


(See figure on previous page.)

Fig. $\mathbf{6}$ a Results from Bayesian clustering (STRUCTURE), b spatial distribution patterns of within lineage genetic groups and $\mathbf{c}$ relationship between genetic differentiation and geographical distance for the two $B$. alpinus lineages ( $A$ and $B$ ). a Bayesian assignment probabilities of $A$ and $B$ individuals into six and two inferred clusters, respectively. Each individual is represented by a vertical line ( $x$ axis) partitioned into $K$ colored segments that represent the individual's estimated membership proportion in each of the $K$ clusters ( $y$ axis). Sampling site labels (letters along the $x$ axis) are identical to Fig. 1 (see also Additional file 1). $\mathbf{b}$ Membership probabilities averaged across all individuals per population for lineages $A$ and $B$. The colors correspond to colors in panel (a). c Relationship between within-lineage pairwise population differentiation $\left(F_{S T}\right)$ and Euclidean distances. Pairwise population affiliation comprising identical or different sub-clusters is indicated with a number or "diff", respectively. Each population was assigned to the genetic cluster with the highest probability across individuals (e.g., the lineage $A$ population in the top left corner of (b) would be assigned to yellow)

maxillary palp was higher in $A(12-18)$ than in $B(5-10)$ as was the number of rows of setae on the dorsal margin of the femora $(A: 2-3 ; B: 1$; see Additional file 6). Moreover, within part of the nuclear subgroups, the triangular spines of the distal margins of tergum IV were more irregular. The margins of the gills IV also presented variation in serration and in the way the setae are grouped. Other characters exhibited variation, but variation in these characters could not be attributed consistently to nuclear subgroups.

\section{Discussion}

\section{Evidence for cryptic species}

In this comprehensive study, we show that the nominal species $B$. alpinus comprises at least two evolutionarily distinct lineages in the central Alps that can be considered separate species under the unified species concept [28]. Several lines of evidence support this interpretation. First, both nuclear and mitochondrial markers clearly separate these two genetic entities and delineate the same genetic groupings, suggesting that these cryptic lineages have been evolving separately for extended periods of time. Second, divergence based on both the between-lineage pairwise $F_{\mathrm{ST}} \mathrm{S}$ of microsatellite markers (0.189) and mitochondrial COI sequence divergence $(18.9 \%)$ are in agreement with values reported between other congeneric species (e.g., B. nubecularis and B. melanonyx in our study, see also [19-21,31]). Third, and most importantly, in spite of widespread sympatric occurrence of both $B$. alpinus lineages in the study area, only $3 \%$ of the 1591 individuals represented intermediate genotypes (i.e., genetically admixed individuals), suggesting at most very rare hybridization. Extremely low levels of gene flow among the lineages are further supported by the observation that individuals consistently clustered by genetic group independent of their geographic origin. For example, individuals from lineage $A$ always clustered with other $A$ individuals even from geographically distant sites rather than $B$ individuals from the same site. Finally, a preliminary morphological analysis of the cryptic lineages, revealed subtle but consistent morphological differences in several traits. In most cases, the observed differences were previously already known but were considered as intraspecific variation $[88,60]$.

\section{Biogeography and evolutionary history of the cryptic lineages}

Our mtDNA sequence data allowed us to relate genetic diversity of $B$. alpinus from our study region to genetic diversity found in other European studies. We found that $B$. alpinus haplotypes sharing high sequence similarity to those found in Switzerland (our study) have been reported from other European mountain ranges: central Apennines, Ligurian Apennines, Pyrenees and Sierra Nevada (Fig. 3, Additional file 1: Table S3), indicating
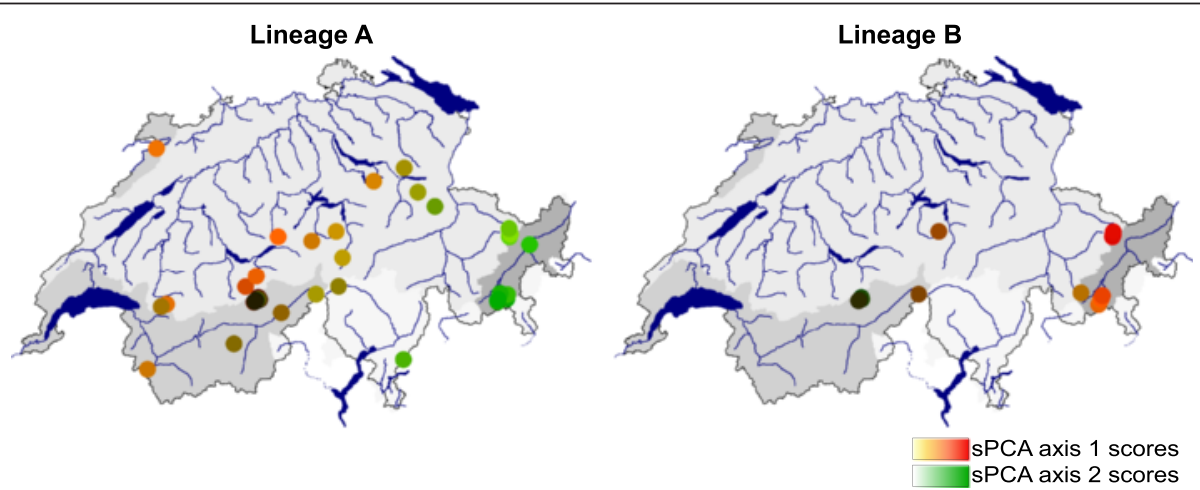

Fig. 7 Results of spatial principal component analysis on B. alpinus lineages $A$ and $B$. Each dot synthesizes the first two sPCA principal components (see [80]), which are plotted on a red (SPCA PC1) or green (SPCA PC2) color scale. The color intensity is proportional to the spatial principal component scores so that populations that are more closely related in multivariate space are similar in color 
that both cryptic lineages have a wide European distribution. Furthermore, lineage $A$ and $B$ individuals from our study showed strong genetic affinities with two of the four unique evolutionary entities previously identified from the Pyrenees and Sierra Nevada [23]. While two lineage $A$ haplotypes observed in our study were also found in the Maritime Alps (Fig. 3), there is also clear evidence of genetic differentiation (within each of the cryptic lineages) between samples collected in the central Alps in Switzerland and other European mountain ranges (Fig. 3). This genetic divergence is most likely due to spatial isolation among mountain massifs.

The broad European distribution of the cryptic lineages suggests that they diverged during past geographic isolation (i.e., in allopatry) and were brought into secondary contact upon range expansion. This scenario is further supported by the observation that individuals consistently clustered by genetic lineage rather than by geographic origin, suggesting a common evolutionary history of all populations within a species. Hence, the divergence observed here likely follows a pattern seen in many European plants and animals due to past changes in global climate and related range contractions (and divergence in isolation) and expansions (secondary contact) (see [89] for a review). However, further phylogeographic studies across the entire European distribution range of $B$. alpinus are clearly needed to understand the evolutionary history of these cryptic lineages.

While it seems likely (based on genetic data and known glacial history of Europe) that the initial divergence occurred in allopatry, it is possible that barriers to gene flow between these incipient species have continued to accumulate after secondary contact [90]. Today, multiple types of ecological and non-ecological barriers may contribute to the observed reproductive isolation between the two cryptic lineages. Putative pre-mating barriers could involve, for example, assortative mating based on non-visual cues (e.g., pheromones) or mismatches in genitalia that prevent interspecific mating [91] - as seen in many insect taxa. Premating isolation could also occur if adults from different lineages do not meet during the mating season, for instance, due to differences in the location or time where mating swarms are formed. Spatial and temporal segregation of mating swarms have been reported in several aquatic insects (e.g., [92]), and our own data suggest pronounced phenological differences between lineage $A$ and $B$ (Leys et al., unpublished data; see also below). Finally, post-zygotic intrinsic barriers due to genetic incompatibilities, as well as extrinsic barriers due to reduced viability or fertility of migrants and hybrids, may play an important role in impeding gene flow and recombination [93]. However, as little is known of mating barriers in baetid mayflies, an important next step is to understand the mechanisms of reproductive isolation in this putative cryptic species complex.

\section{Differences between the cryptic lineages}

The determinants of phenotypically similar but genetically distinct cryptic lineages are diverse, ranging from phenotypic plasticity to non-visual mating signals and morphological stasis [2]. In our study, much of these are still unknown, but analyses of spatial patterns of habitat affiliation, abundance and population genetic variation certainly indicate differences in ecology or population demography - despite relative morphological similarity.

First, the wide geographic ranges and, in particular, frequent sympatric co-occurrence suggest that these $B$. alpinus cryptic lineages can coexist, as also suggested by the patterns observed in other European mountain massifs (e.g., in the Cirque de Taillon in the Pyrenees [23]). Stable coexistence of species is typically thought to require some ecological differentiation or spatio-temporal niche partitioning to reduce inter-specific competition [94]. Our data provide tentative evidence for differences between the lineages in relation to spatial variation in ecological factors (in particular, altitude and stream type): the relative abundance of lineage $B$ was greater at high elevations and in spring-fed tributaries. Microhabitat affiliation may result from inter-specific differences in local habitat use by adults for breeding and/or suitable habitats for development of embryos and larvae. Temporal niche segregation may also be important in $B$. alpinus. Our spatio-temporally replicated data in two basins (Leys et al., unpubl. data) indicates that lineage $A$ and $B$ differ in larval cohort structure and hence in lifehistory strategies (i.e., voltinism). Ongoing work is investigating to what extent these differences are driven by environmental variation and relate to temporal differences in adult emergence times.

Second, we found that lineage $A$ was clearly more abundant than lineage $B$ and showed higher levels of population genetic variation. $B$. alpinus lineage $B$ appears to be more patchily distributed but relatively more abundant at high elevations, and exhibits lower genetic diversity (in terms of allelic richness and heterozygosity), than lineage $A$. The differences in genetic diversity between lineage $A$ and $B$ may be explained by spatial distribution and demographic processes. A potentially lower effective and demographic population size, lower evolutionary potential and greater extinction risk may be of particular concern with respect to biodiversity loss expected as a result of ongoing global change $[95,7,10]$. In this context, the fate of alpine taxa under climate change may be grim. In particular for taxa, such as the spatially more isolated lineage $B$ that appears to have narrower habitat preferences, an upstream distributional 
shift to higher elevation sites is not possible once glaciers disappear.

\section{Within lineage substructure}

We found clear genetic structure within each of the lineages. In particular, within lineage $A$ there are additional genetic subgroups indicating some level of reproductive isolation or reduced gene flow. This possibility is supported by at least two lines of evidence. First, in several cases neighbouring lineage $A$ populations showed pronounced differences in genetic composition. A particularly striking example is that the individuals from spring-fed tributaries in Loetschental appear to belong to a genetic cluster completely absent from other nearby sites (purple in Fig. 6a). Moreover, the genetic differentiation between populations of lineage $A$, which are assigned to different genetic subgroups, was largely independent of the geographical distance between them (light grey points labelled "diff" in Fig. 6c). It remains to be further investigated if some of these subgroups result from genetic drift following colonization-extinction dynamics [96, 97] or represent additional evolutionarily distinct units, perhaps adapted to different environmental conditions [98].

We also found clear evidence for east-west genetic clines in both lineages, this pattern being more pronounced in lineage $B$ (Figs. $6 \mathrm{~b}$ and 7). Indeed, the latter lineage showed consistently both nuclear and mtDNA eastern-western spatial structures. These genetic clines do not coincide with any obvious environmental gradient across the study area and could have resulted from past demographic processes during past climatic events (e.g., isolation in allopatry and recolonization dynamics [99]). However, this hypothesis must be further tested using samples across B. alpinus' entire distribution range.

\section{Conclusions}

We show that the common B. alpinus mayfly comprises at least two distinct evolutionary units within the central Alps. Although these lineages were previously assigned to the same morphospecies based on taxonomic characteristics, our data clearly show that they are genetically, ecologically and morphologically distinct. Our study further emphasizes the need of a phylogenetic reconstruction together with morphological and taxonomic description across the full distributional range of $B$. alpinus to infer the evolutionary history of the cryptic species. In general, our study highlights the need to apply molecular analyses of divergence even in taxonomically and ecologically well-studied species: the correct identification of cryptic species is critical for meaningful inferences about biodiversity loss and evolutionary potential in face of global change.

\section{Availability of supporting data}

Nuclear microsatellite data is available in DRYAD (doi: 10.5061/dryad.74458). Mitochondrial COI sequences have been deposited at the ENA database (accessions LT546400 - LT546427). The supporting results and data are provided as Additional files 1, 2, 3, 4, 5 and 6 .

\section{Additional files}

\begin{abstract}
Additional file 1: Supplementary tables. Table S1. Sampling site information and population genetic diversity estimates. Table S2. Characteristics and amplification conditions of Baetis alpinus microsatellite loci used in this study. Table S3. List of available published sequences from GenBank and unpublished sequences used in this study. Table S4. COI sequence divergence between clades. Table S5. Locus-specific and multilocus genetic diversity and differentiation estimates. Table S6. Null allele frequency estimates. Table S7. Generalized linear model results. (PDF $175 \mathrm{~kb}$ )
\end{abstract}

Additional file 2: Bayesian clustering results of STRUCTURE and evidence of multimodality. (PDF $223 \mathrm{~kb}$ )

Additional file 3: Parsimony haplotype network analysis. (PDF 159 kb)

Additional file 4: Results from Bayesian clustering (STRUCTURE). (PDF 898 kb)

Additional file 5: Genetic transitive graphs. (PDF $1217 \mathrm{~kb}$ )

Additional file 6: Morphological analysis of $B$. alpinus lineage larval structures. (PDF 8912 kb)

Competing interests

The authors declare that they have no competing interests.

Authors' contributions

$M L, I K, K R$ and CTR conceived and designed the study. ML, IK and CTR performed field sampling. J-LG conducted the morphological analysis. ML carried out the laboratory work, analyzed the data and prepared the first manuscript draft and all authors contributed substantially to the writing of the manuscript. All authors read and approved the final manuscript.

\section{Acknowledgments}

Data analyzed in this paper were generated at the Genetic Diversity Centre (GDC), ETH Zurich. We warmly thank S. Blaser for field technical support, L. Breithut for carrying out the mtDNA sequencing, M. Seymour for mapping data and statistical hints, M. Sartori for insights on morphology and support, S. Rutschmann and the Leibniz Association (PAKT für Forschung und Innovation - FREDIE; www.leibniz-gemeinschaft.de) for providing COI unpublished sequences, S. Gallina and S. Zoller for computing assistance with Bayesian clustering, M. Symonds, the Axios associate editor and three anonymous reviewers for very helpful comments on the manuscript, and the Swiss National Foundation for financial support (Grant No. 31003A_135523).

\section{Author details}

${ }^{1}$ Department of Aquatic Ecology, EAWAG, Swiss Federal Institute of Aquatic Science and Technology, Ueberlandstrasse 133, CH-8600 Dübendorf, Switzerland. ${ }^{2}$ Institute of Integrative Biology, ETH-Zürich, CH-8092 Zürich, Switzerland. ${ }^{3}$ Department of Clinical Research, University of Bern and Swiss Institute of Bioinformatics, CH-3010 Bern, Switzerland. ${ }^{4}$ Musée cantonal de Zoologie, Palais de Rumine, Place de la Riponne 6, CH-1014 Lausanne, Switzerland. ${ }^{5}$ Department of Ecology and Evolution, University of Lausanne, Biophore, CH -1015 Lausanne, Switzerland.

Received: 3 March 2016 Accepted: 23 March 2016

Published online: 12 April 2016

\section{References}

1. Via S, Gomulkiewicz R, Dejong G, Scheiner SM, Schlichting CD, Vantienderen $\mathrm{PH}$. Adaptive phenotypic plasticity: consensus and controversy. Trends Ecol Evol. 1995;10(5):212-7. 
2. Bickford D, Lohman DJ, Sodhi NS, Ng PKL, Meier R, Winker K, Ingram KK, Das I. Cryptic species as a window on diversity and conservation. Trends Ecol Evol. 2007;22(3):148-55.

3. Pfenninger M, Schwenk K. Cryptic animal species are homogeneously distributed among taxa and biogeographical regions. BMC Evol Biol. 2007;7:121.

4. Vodă R, Dapporto L, Dincă V, Vila R. Cryptic matters: overlooked species generate most butterfly beta-diversity. Ecography. 2015;38(4):405-9.

5. Crandall KA, Bininda-Emonds ORP, Mace GM, Wayne RK. Considering evolutionary processes in conservation biology. Trends Ecol Evol. 2000;15(7):290-5.

6. Trontelj P, Fišer C. Cryptic species diversity should not be trivialised. Syst Biodivers. 2009:7:1-3.

7. Bálint $\mathrm{M}$, Domisch $\mathrm{S}$, Engelhardt CHM, Haase P, Lehrian S, Sauer J, Theissinger K, Pauls SU, Nowak C. Cryptic biodiversity loss linked to global climate change. Nat Clim Chang. 2011;1(6):313-8.

8. Feckler A, Zubrod JP, Thielsch A, Schwenk K, Schulz R, Bundschuh M. Cryptic species diversity: an overlooked factor in environmental management? J Appl Ecol. 2014:51(4):958-67.

9. Macher JN, Salis RK, Blackemore KS, Tollrian R, Matthaei CD, Leese F. Multiple-stressor effects on stream invertebrates: DNA barcoding reveals contrasting responses of cryptic mayfly species. Ecol Indic. 2016;61:159-69.

10. Pauls SU, Nowak C, Bálint M, Pfenninger M. The impact of global climate change on genetic diversity within populations and species. Mol Ecol. 2013;22(4):925-46.

11. Milner AM, Brown LE, Hannah DM. Hydroecological response of river systems to shrinking glaciers. Hydrol Process. 2009;23(1):62-77.

12. Jacobsen D, Milner AM, Brown LE, Dangles O. Biodiversity under threat in glacier-fed river systems. Nat Clim Chang. 2012;2(5):361-4.

13. Cauvy-Fraunié S, Espinosa R, Andino P, Dangles O, Jacobsen D. Relationships between stream macroinvertebrate communities and new flood-based indices of glacial influence. Freshw Biol. 2014;59(9):1916-25.

14. Jackson JK, Battle JM, White BP, Pilgrim EM, Stein ED, Miller PE, Sweeney BW. Cryptic biodiversity in streams: a comparison of macroinvertebrate communities based on morphological and DNA barcode identifications. Freshwater Science. 2014:33(1):312-24.

15. Vuataz L, Sartori M, Wagner A, Monaghan MT. Toward a DNA Taxonomy of Alpine Rhithrogena (Ephemeroptera: Heptageniidae) Using a Mixed Yule Coalescent Analysis of Mitochondrial and Nuclear DNA. Plos One. 2011;6(5):e19728.

16. Rutschmann S, Gattolliat J-L, Hughes SJ, Baez M, Sartori M, Monaghan MT. Evolution and island endemism of morphologically cryptic Baetis and Cloeon species (Ephemeroptera, Baetidae) on the Canary Islands and Madeira. Freshw Biol. 2014;59:2516-27.

17. Sroka P, Godunko RJ, Novikova EA, Kluge NJ. Contribution to the knowledge of the subgenus Rhodobaetis Jacob, 2003 (Ephemeroptera: Baetidae: Baetis) from Central Asia. Part 1. Zootaxa. 2012:3311:42-60.

18. Hughes JM, Mather PB, Hillyer MJ, Cleary C, Peckarsky B. Genetic structure in a montane mayfly Baetis bicaudatus (Ephemeroptera: Baetidae), from the Rocky Mountains, Colorado. Freshw Biol. 2003;48(12):2149-62.

19. Williams HC, Ormerod SJ, Bruford MW. Molecular systematics and phylogeography of the cryptic species complex Baetis rhodani (Ephemeroptera, Baetidae). Mol Phylogenet Evol. 2006;40(2):370-82.

20. Stahls G, Savolainen E. MtDNA COI barcodes reveal cryptic diversity in the Baetis vernus group (Ephemeroptera, Baetidae). Mol Phylogenet Evol. 2008:46(1):82-7.

21. Pereira-da-Conceicoa LL, Price BW, Barber-James HM, Barker NP, de Moor FC, Villet MH. Cryptic variation in an ecological indicator organism: mitochondrial and nuclear DNA sequence data confirm distinct lineages of Baetis harrisoni Barnard (Ephemeroptera: Baetidae) in southern Africa. BMC Evol Biol. 2012;12:26.

22. Finn DS, Khamis K, Milner AM. Loss of small glaciers will diminish beta diversity in Pyrenean streams at two levels of biological organization. Glob Ecol Biogeogr. 2013:22(1):40-51.

23. Finn DS, Zamora-Muñoz C, Múrria C, Sáinz-Bariáin M, Alba-Tercedor J. Evidence from recently deglaciated mountain ranges that Baetis alpinus (Ephemeroptera) could lose significant genetic diversity as alpine glaciers disappear. Freshwater Science. 2014;33(1):207-16.

24. Múrria C, Morante M, Rieradevall M, Ribera C, Prat N. Genetic diversity and species richness patterns in Baetidae (Ephemeroptera) in the Montseny Mountain range (North-East Iberian Peninsula). Limnetica. 2014;33(2):313-26.
25. Gattolliat J-L, Cavallo E, Vuataz L, Sartori M. DNA barcoding of Corsican mayflies (Ephemeroptera) with implications on biogeography, systematics and biodiversity. Arthropod Systematics Phylogeny. 2015;73(1):3-18.

26. Lepori F, Ormerod SJ. Effects of spring acid episodes on macroinvertebrates revealed by population data and in situ toxicity tests. Freshw Biol. 2005;50(9):1568-77.

27. Dijkstra KDB, Monaghan MT, Pauls SU. Freshwater biodiversity and aquatic insect diversification. Annu Rev Entomol. 2014:59:143-63.

28. De Queiroz K. Species concepts and species delimitation. Syst Biol. 2007;56(6):879-86.

29. Mallet J. A species definition for the modern synthesis. Trends Ecol Evol. 1995;10(7):294-9.

30. Hebert PDN, Cywinska A, Ball SL, DeWaard JR. Biological identifications through DNA barcodes. Proc R Soc B-Biol Sci. 2003;270(1512):313-21.

31. Ball SL, Hebert PDN, Burian SK, Webb JM. Biological identifications of mayflies (Ephemeroptera) using DNA barcodes. J N Am Benthol Soc. 2005:24(3):508-24

32. Bensasson D, Zhang DX, Hartl DL, Hewitt GM. Mitochondrial pseudogenes: evolution's misplaced witnesses. Trends Ecol Evol. 2001:16(6):314-21.

33. Ballard JWO, Whitlock MC. The incomplete natural history of mitochondria. Mol Ecol. 2004:13(4):729-44.

34. Funk DJ, Omland KE. Species-level paraphyly and polyphyly: Frequency, causes, and consequences, with insights from animal mitochondrial DNA. Annu Rev Ecol Evol Syst. 2003;34:397-423.

35. Toews DPL, Brelsford A. The biogeography of mitochondrial and nuclear discordance in animals. Mol Ecol. 2012;21(16):3907-30.

36. Cheng S, Lee CT, Wan MN, Tan SG. Microsatellite markers uncover cryptic species of Odontotermes (Termitoidae: Termitidae) from Peninsular Malaysia. Gene. 2013;518(2):412-8.

37. Hoekzema K, Sidlauskas BL. Molecular phylogenetics and microsatellite analysis reveal cryptic species of speckled dace (Cyprinidae: Rhinichthys osculus) in Oregon's Great Basin. Mol Phylogenet Evol. 2014;77:238-50.

38. Andrews KR, Norton EL, Fernandez-Silva I, Portner E, Goetze E. Multilocus evidence for globally distributed cryptic species and distinct populations across ocean gyres in a mesopelagic copepod. Mol Ecol. 2014;23(22):5462-79.

39. Wang H-L, Yang J, Boykin LM, Zhao Q-Y, Wang Y-J, Liu S-S, Wang X-W. Developing conversed microsatellite markers and their implications in evolutionary analysis of the Bemisia tabaci complex. Sci Rep. 2014:4:6351.

40. Racey PA, Barratt EM, Burland TM, Deaville R, Gotelli D, Jones G, Piertney SB. Microsatellite DNA polymorphism confirms reproductive isolation and reveals differences in population genetic structure of cryptic pipistrelle bat species. Biol J Linn Soc. 2007;90(3):539-50.

41. Westram AM, Jokela J, Keller I. Hidden biodiversity in an ecologically important freshwater amphipod: differences in genetic structure between two cryptic species. Plos One. 2013;8(8):e69576.

42. Knispel S, Sartori M, Brittain JE. Egg development in the mayflies of a Swiss glacial floodplain. J N Am Benthol Soc. 2006;25(2):430-43.

43. Humpesch UH. Life cycles and growth rates of Baetis spp. (Ephemeroptera: Baetidae) in the laboratory and in two stony streams in Austria. Freshw Biol. 1979;9(5):467-79.

44. Schmidt SK, Hughes JM, Bunn SE. Gene flow among conspecific populations of Baetis sp. (Ephemeroptera): adult flight and larval drift. J N Am Benthol Soc. 1995:14(1):147-57.

45. Müller-Liebenau I. Revision der europaischen Arten der Gattung Baetis Leach, 1815 (Insecta, Ephemeroptera). Gewässer und Abwässer. 1969;48/49:1-214.

46. Bauernfeind E, Soldan T. The mayflies of Europe (Ephemeroptera). Ollerup, Denmark: Appollo Books; 2012.

47. Thomas AGB, Gazagnes G. Baetis cyrneus n. sp., Ephéméroptère nouveau de Corse (Baetidae). Ann Limnol. 1984;20(3):199-202.

48. Sartori M. New records and redescription of Baetis nubecularis Eaton, 1898 from the Swiss Jura (Ephemeroptera, Baetidae). Aquat Insects. 1985;7(4):209-14

49. Breitenmoser-Würsten C, Sartori M. Distribution, diversity, life cycle and growth of a mayfly community in a prealpine stream system (Insecta, Ephemeroptera). Hydrobiologia. 1995;308(2):85-101.

50. Lavandier P. Evidence of upstream migration by female adults of Baetis alpinus (Ephemeroptera) at high altitude in the Pyrenees. Ann Limnol. 1982;18(1):55-60.

51. Lavandier P. Semivoltinism in high mountain populations of Baetis alpinus Pictet. (Ephemeroptera). Bulletin de la Société d'Histoire Naturelle de Toulouse. 1988;124:61-4. 
52. Kukula K. The life cycles of three species of Ephemeroptera in two streams in Poland. Hydrobiologia. 1997;353:193-8.

53. Erba S, Melissano L, Buffagni A. Life cycles of Baetidae (Insecta: Ephemeroptera) in a North Italian Prealpine stream. In: Gaino E, editor. Research update on Ephemeroptera and Plecoptera. Perugia, Italy: University of Perugia Press; 2003. p. 177-86.

54. López-Rodríguez MJ, de Figueroa JMT, Alba-Tercedor J. Life history and larval feeding of some species of Ephemeroptera and Plecoptera (Insecta) in the Sierra Nevada (Southern Iberian Peninsula). Hydrobiologia. 2008;610:277-95.

55. Ward JV, Stanford JA. Thermal responses in the evolutionary ecology of aquatic insects. Annu Rev Entomol. 1982;27:97-117.

56. Sartori M, Landolt P. Atlas de distribution des éphémères de Suisse (Insecta, Ephemeroptera), vol. 3. Neuchâtel, Switzerland: SEG-CSCF; 1999.

57. Studemann D, Landolt P, Sartori M, Hefti D, Tomka I. Ephemeroptera. Insecta helvetica, Fauna 9. Fribourg, Switzerland: Imprimerie Mauron, Tinguely and Lachat SA; 1992.

58. Ward JV, Malard F, Tockner K, Uehlinger U. Influence of ground water on surface water conditions in a glacial flood plain of the Swiss Alps. Hydrol Process. 1999;13(3):277-93.

59. Füreder $L$, Schütz $C$, Wallinger $M$, Burger R. Physico-chemistry and aquatic insects of a glacier-fed and a spring-fed alpine stream. Freshw Biol. 2001:46(12):1673-90

60. Bauernfeind E, Humpesch UH. Die Eintagsfliegen Zentraleuropas (Insecta: Ephemeroptera): Bestimmung und Oekologie. Wien, Austria: Verlag des Naturhistorischen Museums Wien; 2001

61. Sunnucks P, England PR, Taylor AC, Hales DF. Microsatellite and chromosome evolution of parthenogenetic Sitobion aphids in Australia. Genetics. 1996;144(2):747-56.

62. Dawson DA, Horsburgh GJ, Kupper C, Stewart IRK, Ball AD, Durrant KL, Hansson B, Bacon I, Bird S, Klein A, et al. New methods to identify conserved microsatellite loci and develop primer sets of high cross-species utility - as demonstrated for birds. Mol Ecol Resour. 2010;10(3):475-94.

63. Folmer O, Black M, Hoeh W, Lutz R, Vrijenhoek R. DNA primers for amplification of mitochondrial cytochrome c oxidase subunit I from diverse metazoan invertebrates. Mol Mar Biol Biotechnol. 1994;3(5):294-9.

64. Hall TA. BioEdit: a user-friendly biological sequence alignment editor and analysis program for Windows 95/98/NT. Nucleic Acids Symp Ser. 1999;41:95-8.

65. Goudet J. FSTAT (Version 1.2): A computer program to calculate F-statistics. J Hered. 1995;86(6):485-6.

66. Raymond M, Rousset F. GENEPOP (Version-1.2) - Population genetics software for exact tests and ecumenicism. J Hered. 1995;86(3):248-9.

67. Dempster AP, Laird NM, Rubin DB. Maximum Likelihood from incomplete data via the EM Algorithm. J R Stat Soc Ser B Methodol. 1977;39:1-38.

68. Pritchard JK, Stephens M, Donnelly P. Inference of population structure using multilocus genotype data. Genetics. 2000;155(2):945-59.

69. Falush D, Stephens M, Pritchard JK. Inference of population structure using multilocus genotype data: linked loci and correlated allele frequencies. Genetics. 2003;164(4):1567-87.

70. Evanno G, Regnaut S, Goudet J. Detecting the number of clusters of individuals using the software STRUCTURE: a simulation study. Mol Ecol. 2005;14(8):2611-20.

71. Meirmans PG. Seven common mistakes in population genetics and how to avoid them. Mol Ecol. 2015;24(13):3223-31.

72. Jakobsson M, Rosenberg NA. CLUMPP: a cluster matching and permutation program for dealing with label switching and multimodality in analysis of population structure. Bioinformatics. 2007;23(14):1801-6.

73. Rosenberg NA. DISTRUCT: a program for the graphical display of population structure. Mol Ecol Notes. 2004;4(1):137-8.

74. Jombart T, Devillard S, Balloux F. Discriminant analysis of principal components: a new method for the analysis of genetically structured populations. BMC Genet. 2010;11:94.

75. Jombart T. ADEGENET: a R package for the multivariate analysis of genetic markers. Bioinformatics. 2008;24(11):1403-5.

76. Paradis E, Claude J, Strimmer K. APE: Analyses of Phylogenetics and Evolution in R language. Bioinformatics. 2004;20(2):289-90.

77. Guindon S, Gascuel O. A simple, fast, and accurate algorithm to estimate large phylogenies by maximum likelihood. Syst Biol. 2003;52(5):696-704.

78. Zuur AF, leno EN, Walker NJ, Saveliev AA, Smith GM. Mixed effects models and extensions in ecology with R. New York: Springer; 2009.
79. R Core Team. R: A language and environment for statistical computing. Vienna, Austria: R Foundation for Statistical Computing; 2015.

80. Jombart T, Devillard S, Dufour AB, Pontier D. Revealing cryptic spatial patterns in genetic variability by a new multivariate method. Heredity. 2008;101(1):92-103.

81. Frantz AC, Cellina S, Krier A, Schley L, Burke T. Using spatial Bayesian methods to determine the genetic structure of a continuously distributed population: clusters or isolation by distance? J Appl Ecol. 2009;46(2):493-505.

82. Schwartz MK, McKelvey KS. Why sampling scheme matters: the effect of sampling scheme on landscape genetic results. Conserv Genet. 2009;10(2):441-52.

83. Menozzi P, Piazza A, Cavalli-Sforza L. Synthetic maps of human genefrequencies in Europeans. Science. 1978;201(4358):786-92.

84. Weir BS, Cockerham CC. Estimating F-statistics for the analysis of population structure. Evolution. 1984;38(6):1358-70.

85. El Mousadik A, Petit RJ. High level of genetic differentiation for allelic richness among populations of the argan tree Argania spinosa $(L)$ Skeels endemic to Morocco. Theor Appl Genet. 1996;92(7):832-9.

86. Szpiech ZA, Jakobsson M, Rosenberg NA. ADZE: a rarefaction approach for counting alleles private to combinations of populations. Bioinformatics. 2008;24(21):2498-504.

87. Siegel S, Castellan NJ. Non parametric statistics for the behavioural sciences. New York: MacGraw Hill Int; 1988.

88. Peru $\mathrm{N}$, Thomas $\mathrm{A}$. Compléments et corrections à la faune des Ephéméroptères d'Afrique du Nord. 7. Description complémentaire de Baetis berberus Thomas, 1986 (Ephemeroptera, Baetidae). Ephemera. 2003:3(2):75-82

89. Hewitt GM. Genetic consequences of climatic oscillations in the Quaternary. Philos Trans R Soc Lond Ser B Biol Sci. 2004;359(1442):183-95.

90. Coyne JA, Orr HA. Speciation. Sunderland, MA: Sinauer Associates; 2004.

91. Sota T, Kubota K. Genital lock-and-key as a selective agent against hybridization. Evolution. 1998;52(5):1507-13.

92. Savolainen E, Saura A, Hantula J. Mode of swarming in relation to reproductive isolation in mayflies. Evolution. 1993;47(6):1796-804.

93. Seehausen O, Butlin RK, Keller I, Wagner CE, Boughman JW, Hohenlohe PA, Peichel CL, Saetre G-P, Bank C, Braennstroem A. Genomics and the origin of species. Nat Rev Genet. 2014;15(3):176-92.

94. Chesson P. Mechanisms of maintenance of species diversity. Annu Rev Ecol Syst. 2000;31:343-66.

95. Wagner A, Sartori M. Liste rouge des Ephémères de Suisse. In: Lubini V, Knispel S, Sartori M, Vicentini FL, Wagner A, editors. Listes rouges Ephémères, Plécoptères Trichoptères: Espèces menacées en Suisse, état 2010. Bern: Office fédéral de l'Environnement \& Centre Suisse de Cartographie de la Faune; 2012.

96. Caudill CC. Empirical evidence for nonselective recruitment and a sourcesink dynamic in a mayfly metapopulation. Ecology. 2003;84(8):2119-32.

97. Bunn SE, Hughes JM. Dispersal and recruitment in streams: Evidence from genetic studies. J N Am Benthol Soc. 1997;16(2):338-46.

98. Bohonak AJ, Jenkins DG. Ecological and evolutionary significance of dispersal by freshwater invertebrates. Ecol Lett. 2003;6(8):783-96.

99. Elbrecht V, Feld CK, Gies M, Hering D, Sondermann M, Tollrian R, Leese F. Genetic diversity and dispersal potential of the stonefly Dinocras cephalotes in a central European low mountain range. Freshwater Science. 2014;33(1):181-91.

\section{Submit your next manuscript to BioMed Central and we will help you at every step:}

- We accept pre-submission inquiries

- Our selector tool helps you to find the most relevant journal

- We provide round the clock customer support

- Convenient online submission

- Thorough peer review

- Inclusion in PubMed and all major indexing services

- Maximum visibility for your research

Submit your manuscript at www.biomedcentral.com/submit 